\title{
I. Remarks on Damp Decks, and other circumstances in the Medical œconomy of ships
}

\section{A Naval Surgeon}

To cite this article: A Naval Surgeon (1820) I. Remarks on Damp Decks, and other circumstances in the Medical œconomy of ships , Philosophical Magazine Series 1, 55:261, 3-8, DOI: $10.1080 / 14786442008652267$

To link to this article: http://dx.doi.org/10.1080/14786442008652267

曲 Published online: 29 Jul 2009.

Submit your article to this journal $₫$

Џll Article views: 3

Q View related articles $₫$ 


\title{
PHILOSOPHICAL MAGAZINE
}

\section{AND JOURNAL.}

I. Remarks on Damp Derks, and other Circumstances in the Medical Economy of Ships. By A Navar. Surgeon.

\author{
To Mr. Tilloch.
}

SIR, - $\mathbf{I}_{\mathbf{N}}$ allowing in your valuable miscellany [The Philosophical Magazine] immediate publicity to the following remarks on Damp Decks, \&c. you will, in all probability; particularly in such humid weather as the present, render an essential service to that useful class of men for whose benefit they are solely intended.

I have the honour to be, sir,

Your most obedient and very humble servant,

Portsmouth, Dec. 22, 1819.

A Naval Surgeon.

\section{Damp Decks, \&̊c.}

“The ship, in the first place, by frequent drying and ventilation, is preserved from damp and foul air."-Dr. Parr's London Medical Dictionary, art. Scorb.

A suIp in the midst of the deep, having by far its greater part jmmersed beneath the surface, is a circumstance that suggests to us the natural formation and collection of vapour in it, and likewise the difficulty of its extrication, on the additional considerations of the nature of the one and of the form and structure of the other.

Besides, water insinuates itself more or less into the holds of all ships, which, with the water in casks, \&c. must in a greater or less degree be productive of vapour. If to this be added the great portion of steam which arises at the meals, \&c. and the great quantity of exspirated vapour thrown out byseveral hundreds of men so closely situated, the quantity of vapour thus collected, is so great as to need an incessant extrication of it, particularly when we consider its intermixture with what is implied by the foul air of ships ; namely, air consisting of a redundancy of carbonic acid and an excess of azote, or deficiency of oxygen from

Vol. 55. No. 261. Jan. 1820.

A 2

the 
the partial renovation of its consumption ; and likewise, in a certain degree, notious gases, arising from animal effluvia, especially that contained in unaired bedding, unwashed clothes, \&c. and the putrefaction, however slow, of provisions; all which render it the more noxious.

Reflections on this invariable tendency to moisture, and on the abovementioned particulars, point out the extreme necessity of keeping the decks and cabins of ships as dry, yet clean, as possible. Experience and science grant, that the internal cleanliness of ships is not only conducive to health, but absolutely essential to the prevention of disease.

The mode of effecting cleanliness is, however, often extremely injudicious, or betrays inconsideration, or something like ignorance. What honest candour extorts, surely will not be ascribed to presumption. How many instances have there been of washing decks, and barely swabbing them after, when the entire atmosphere has teemed with fogs and moisture, without a breath of wind, when stoves have been deemed unnecessary, or not so much as thought of ! To say the truth, under such peculiarities of the atmosphere, common stoves can be of very little use; for the rarefaction produced by their use tends but little, from its slowness, to the extrication of moist air, when wind-sails can be of little or no use. It causes an ascent not entirely to the hatchways, but in part to the beams and planks overhead, where the air thws partially rarefied insinuates itself, or is attracted; and on becoming somewhat condensed, accumulates, until its dispersion by change of weather or alteration of temperature. Hence it is that decks washed in damp weather are often not dry for two, three, four, and even sometimes seven days after. In such states of the air, an exact scrape and clean dry sweep is perhaps the only mode necessary to be adopted.

In frosty weather, or when the temperature is very low, some estimate can be made of the surrounding vapour from its collection and condensation every morning overhead, on the planks and beams of the lower decks and confined cabins.

In the navy, the system of washing or scrubbing hammocks or decks is, like every other system of it, rigid in the extreme. Clothes, as shirts, stockings, \&c. are generally washed or scrubbed twice a-week, by which changes of the same are as often afforded, and are as conducive to comfort as absolutely essential to health. Hammocks, as far as my experience authorizes me to say, are also scrubbed twice, or, at least, once a-week all the year round. In my humble opinion, once a-week in summer or fortnight in winter, and relatively in hot or dry, and cold or moist climates, if not carelessly left about the decks, is adequate to the purposes of cleanliness. Is the frequency beyond this indispensable ? 
sable? or, does it arise from a mere ostentatious principle of useless refinement in bleached hammocks, which, through selfconceit and contrast, glut the eyes of such as virtually have the superintendence of them?

The quarter and main decks are washed every morning at four o'clock, or at day-break, by those who slept-in during the middle watch, or from twelve until the same hour; and the lower decks of frigates, and orlop decks of line-of-battle ships, are washed twice, or, at least, once a-week throughout the year.

I will not presume to determine how often, or precisely when the decks of ships should be wetted; but, by the way, simply observe that the time should be regulated by intervening circumstances; and the less the necessity, and the drier the ship, the healthier it is for ships' companies.

In ships of-the-line, the oeconomy of the sick-bay rests with the surgeon. But as it is comparatively small for the number on an average sick, the patients who have not room to sleep in it, must lie between decks, with the regulation of which he has nothing to do. In frigates the sick are also under the necessity of sleeping on the main deck, unscreened from the strong partial draughts, as well as unprotected from the rude jostle of the thoughtless. These are very sensible of the great alteration of temperature from the early opening of the ports and wetting or washing-of the decks. This sudden alteration of temperature is frequently as much or more than ten degrees. Those who perchance are partially uncovered, instantaneously awake, from the sensations induced by the change, or, if they do not, they are likely to suffer by it; because an immediate alteration of temperature to, or beyond this degree, is known to be generally productive of inflammation.

In detached services, and in long cruizes and voyages, while such a system of washing and slopping prevails, and to which every sacrifice is made, need the dreadful consequences be pointed out? It is nonsense to say that it makes men hardier, or obviates an unnatural tenderness. A learned philosopher and ingenious moral writer, in his inimitable essays, succinctly points out, with his usual discrimination, the dangers arising from the fallacy of such notions.

There are many on board ships variously affected, who yet do not apply to the surgeon for relief, through the fear of being stigmatized as sculkers, or the greater fear of having their allowance of wine or spirits withheld. Such have their hectic exacerbations, and have to turn out of their hammocks, as the phrase is, on these occasions, and strut about the decks for two hours or more, in cold water half way up their legs, handing or dashing it along by buckets full; by which the perspiration becomes suddenly sup- 
pressed, and the body has to encounter the ill effects of the sudden transition from heat to cold, particularly from its long continuance. These observations are in every sense applicable to the predisposed or susceptible ta tubercles, and those diseases by which it is generated.

Spirits and the stronger acids evaporate speedily, and are, to use vulgar language, not vehicles of cold; therefore it is that they obviate the implied effects of it, in stimulating or astringeing the exhalants and integuments of the head, when the hair is cut, or the head or other parts of the body become wet. That the muriatic acid, \&c. contained in sea-water, thus stimulate or astringe, in a certain degree, the exhalants and skin, and therehy overcome the antagonizing agencies of their vehicle, cold water, and the consequent sudden and continued abstraction of calorific from the feet and legs, is in many cases very reasonable to believe; but the privation too long continued counteracts the salutary effects of the stimulating qualities of the acids, induces a change of action in the vessels, and disturbs the circulation.

Moreover, the state of the air of ships from damp decks opposes the cure of acute inflammatory diseases, by unremitting aggravations, and by counteracting the intended effects of a most efficient class of medicines, sudorifies. It is the bane of all chronic complaints, especially chronic rheumatism, the inseparable concomitant of old grog-drinking sailors. It is unfavourable to the cure of ulcers, and really inimical to the cure or palliation of tubercles, and the pulmonic infammations by which, for the most part, it is produced.

It is judiciously ordered that partial draughts of pure atmospheric air be communicated to the lower decks and places of ships in the navy, and that this should at all times be attended to, even though the decks are not washed. This perhaps is the only practice which can be entirely depended on for the extrication of foul air, and therefore should, when practicable, supersede the use of fumigations, which, in my humble opinion, rather tend to conceal than to decompose or dispel it.

I cannut have done with this subject without introducing the following strange remarks, from the recent work of an excellent writer on that grand portion of the earth:

$$
\text { " Semper soli rubens et torrida semper ab igni ;" }
$$

not can I refrain from offering a doctrine different from his, after the liberty which he has expressly and courteousiy given in the Sabine strain, viz.

$$
\text { “ } \mathrm{Si} \text { quid novisti rectius istis, }
$$


"In a ship of-the-line on the home station, I have been in gales of wind during the winter when the decks were floated with water for weeks together, without the possibility of drying them. I have listened night after night to these torrents rushing and roaring from one side of the lower deck to the other, as the ship rolled, while five or six hundred men in hammocks were suspended nightly over the moving current, in the most advantageous manner possible for feeling its influence. And what was the consequence? Why, that there was not a man on the sick list."

"But the scene changes; - the gales subside - the wind veers round to the eastward-we regain our station off the coast of France, where the sea is smooth, the air keen, and the decks perfectly dry. And what is the result? Why, that half the ship's company is laid up with pneumonias."

Taking the truth of both these remarks and replies for granted, - though I cannot but candidly confess they bear to my mind the easy implication of a certain figure of speech-might not this gentleman, with his usual sound reasoning, ascribe the former, should it actually happen, to that certain capability of resistance, for a limited time, in the powers of the healthy constitution to the prejudicial influence of wet and confinement? and the latter, should it actually follow, to that state of susceptibility induced by this circunstance? thereby particularly admitting the subsequent agencies implied in the changes of the scene, when the orthodox doctrine of the ingenious and learned Dr. Brown can be so easily referred to.

Here it is very plainly intimated, that off the coast of France, in winter, an easterly wind, though not strong, has alone been prodictive of pneumonia, although the previous circumstances of living for weeks together between wet decks, of blowing and wet weather, and of a change of wind and weather, are at the same time admitted. The east wind is notorious for its dispersion of moisture; and moisture followed by a wind which disperses it, has a particular influence on temperature. It is thus that the human constitution is acted upon by an easterly wind, and that the brute creation feels its influence. According to the laws of the animal oconomy, the system, from its reaction to the agencies implied in these antecedent circumstances, becomes predisposed, so as to be particularly susceptible of the subsequent agency of the keen easterly wind and of the change of temperature. A sharp easterly wind that has lasted any time, abstractedly considered, without any reference to the weather preceding it, or to the change itself, implies a comparative regularity of a low temperature, which, though it may from its arid qualities aggravate, cannot, in my humble opinion, be solely productive of pneumo- 
nia. I beg leave to refer the reader, who must judge for hímself, to the text for the promissa et consequentia.

For my own part, warm dogmas or positive assertions cannot produce in my mind any conviction, without, at least, some train of reasoning, or axiom of common experience by way of proof ; and I canuot but subscribe my mite to exonerate "some naval surgeons," who have admitted the mischievous consequences of wet or damp decks, from the unjustifiable imputation of embarrassment, and the unbecoming implication of ignorance; since, in addition to what I have just explained, there is no one, either in civilized life, or in the least acquainted with the internal state of a ship, so inexperienced or void of sense, as not to know the very different effects arising from sleeping or remaining in a damp laundry and a dry comfortable apartment, or between damp decks or in a wet galley or manger, and the commodious and ventilated cabin of a commissioned officer or captain, independently of the occurrences of contagion in discipline or drunkenness. Besides, it is observable that laundresses, however accustomed to dampness, are still susceptible of its influence. They are seldom long livers ; for, in general, they die of premature old age, either affected with chronic rheumatism, or affections of the pleura or lungs, produced and repeatedly aggravated by it; nor are their husbands, children, or inmates in winter, scarcely ever entirely free from the same complaints, in consequence of washed clothes being hung up to dry in the rooms in which they sleep or sit.

11. Report from the Select Committee appointed to consider the Validity of the Doctrine of Conlogion in the Plague.

[Concluded from vol. liv. p. 439.]

Dr. William Pym.-W $\mathbf{W}$ s formerly an officer at the quarantine establishment at Malta. 'To be infected by the plague, contact or very near approach to the person under the disease is supposed to be necessary. Believes that it is independent of any disease of the atmosphere. Considers insulation by the means of quarantine, the most effectual step for preventing it. Knows one instance of the plague having been communicated at sea; some French gun-boats were taken by the Theseus man-of-war in the year 1800 , they were ordered alongside, and while lying there, the person ordered on board to issue provisions, \&c. received the infection of the plague. Supposing, as is the case in England, the quarantitie regulations should have been established, and in force for 12 or 14 years, with care, would not the conta- 